\title{
Gérard Wajcman, Les séries, le monde, la crise, les femmes
}

\section{Roberta Sapino}

\section{Q OpenEdition}

1 Journals

\section{Edizione digitale}

URL: https://journals.openedition.org/studifrancesi/21909

DOI: 10.4000/studifrancesi.21909

ISSN: 2421-5856

\section{Editore}

Rosenberg \& Sellier

\section{Edizione cartacea}

Data di pubblicazione: 1 décembre 2019

Paginazione: 627-628

ISSN: 0039-2944

\section{Notizia bibliografica digitale}

Roberta Sapino, «Gérard Wajcman, Les séries, le monde, la crise, les femmes», Studi Francesi [Online], 189 (LXIII | III) | 2019, online dal 01 mars 2020, consultato il 11 novembre 2021. URL: http:// journals.openedition.org/studifrancesi/21909; DOI: https://doi.org/10.4000/studifrancesi.21909

Questo documento è stato generato automaticamente il 11 novembre 2021.

\section{(c) (i) (9)}

Studi Francesi è distribuita con Licenza Creative Commons Attribuzione - Non commerciale - Non opere derivate 4.0 Internazionale. 


\title{
Gérard Wajcman, Les séries, le monde, la crise, les femmes
}

\author{
Roberta Sapino
}

\section{NOTIZIA}

Gérard Wajcman, Les séries, le monde, la crise, les femmes, Lagrasse, Verdier, 2018, 125 pp.

1 Le serie, il mondo, la crisi, le donne: quattro voci giustapposte compongono il titolo del nuovo saggio di Gérard Wajcman, senza alcun connettore logico a esplicitarne i rapporti. E la scelta è tutt'altro che casuale; al contrario, il titolo è una miniatura della contemporaneità così come appare all'occhio vigile dell'autore: parcellizzata, priva di ordine logico e simbolico, inspiegabile attraverso la narrazione. Di questa contemporaneità rappresentabile, seguendo Sloterdijk, con l'immagine di una schiuma, di questo mondo composto di infinite bolle, unità legate da rapporti instabili, troppo mutevoli per creare un'unità compatta, la serie è, afferma Wajcman, la forma: non soltanto nella misura in cui una forma può esprimere e tradurre lo spirito di un'epoca, ma perché la serie ha il potere di dare forma alla contemporaneità rendendola più leggibile, più decifrabile. È quindi la serie in quanto forma, e non solo in quanto genere, ad essere oggetto di analisi in questo saggio che ha il doppio merito di essere raffinato nell'argomentazione e di agevole lettura, e per questo accessibile anche a un pubblico non accademico.

2 Se il cinema è stato in gran parte la fabbrica del mito americano, la serie non solo non produce alcun mito, ma è la forma di una nazione che, disgregandosi, si sbarazza dei propri miti fondatori («Ciné, série», pp. 10-18), mostrando impietosamente le fragilità e le contraddizioni di un'epoca che è nata sulle rovine di Ground Zero («Matrice de l'effondrement», pp. 19-22) e il cui tono è, sostiene Wajcman, quello della crisi perenne («Série de crise», pp. 22-24).

3 La serie è, essenzialmente, la forma della molteplicità, della ripetizione potenzialmente infinita di elementi simili ma non identici: così come la riproducibilità tecnica 
dell'uguale è stata - Benjamin lo insegna - una chiave della modernità, la successione discontinua del diverso appare come la struttura del monde illimité del ventunesimo secolo («La série, œil ouvert sur le monde», pp. 24-38), nel quale l'idea stessa di frontiera si dissolve a vantaggio di modelli fondati sulla fluidità e sulla permeabilità tra spazi e categorie. Come i quadri rinascimentali organizzati secondo prospettiva, la forma della serie garantisce all'uomo una maniera - problematica, instabile, insufficiente - di situarsi nel mondo, in relazione alla quale può cercare di orientarsi a tentoni in «un univers liquide où les sujets comme les histoires sont à la fois multiples, indéfinis et dispersés» («La forme-série», pp. 38-63). «La série est le tableau du monde» («Récit du monde, récit du sujet», pp. 73-82) e per questo motivo può di buon diritto essere considerata in relazione al mito («Mythe, roman, série», pp. 63-68). Tuttavia, non può essere assimilata ad esso: in quanto frutto, specchio e forma di un mondo in cui la «crise du récit» conseguente alla Grande Guerra non trova rimedio, la serie non ha lo stesso potere. «La série sort de la sidération», constata Wajcman, «elle ne nous en sort pas pour autant» («Récit, crise, série», pp. 68-73).

Per capire a pieno la forma della serie bisogna innanzitutto riconoscere che siamo entrati in una nuova era, una nuova civiltà, nella quale valori come l'autorità, la legge e l'ordine hanno perso credibilità a vantaggio di una configurazione sociale fondata sul consumo continuo e illimitato, fino alla dipendenza («Nouvelle civilisation», pp. 82-88). Si spiega così, secondo l'autore, la popolarità della droga in molte serie americane: liberata dallo stigma che la relegava ai margini del socialmente accettabile, la dipendenza (in senso lato: la dipendenza dal piacere, di cui la droga è un'immagine e di cui il binge watching è un sintomo concreto) è diventata una condotta abituale. Se il cinema, con le sue storie ben delimitate da un inizio e una fine, crea desiderio, la serie sollecita e riflette la ricerca della jouissance in termini lacaniani - una ricerca, per definizione, senza confini («La série, topographie de la jouissance», pp. 88-97). Ecco allora comparire, nel ruolo di personaggi principali, modelli umani nuovi, in sintonia con le pulsioni che dominano la civiltà del ventunesimo secolo. Sono le donne che Wajcman chiama déglingueuses: «ce sont les filles d'après la chute de la maison des pères, les filles d'après la révolution», donne libere dai modelli patriarcali senza essere rivoluzionarie, portatrici di disordine senza essere in rivolta, illimitate nella loro potenzialità senza essere granitiche né perfette. Le déglingueuses (una tra tante: l'eroina Marvel Jessica Jones) sono il sintomo di un mondo senza limiti né frontiere, senza ideologie solide né maestri, ma animato da una forza potenzialmente illimitata («Des femmes et des déglingueuses», pp. 98-123).

Studiare Le Serie (O Piuttosto La Serie, In Quanto Forma), Significa Insomma Disegnare Un Vero E Proprio Ritratto Del Nostro Tempo. O, Per Concludere Come L'autore («Dernier Episode», P. 123): «Rien De Plus Sérieux Que Les Séries». 